\title{
PSA Level Less than One Hundred
}

National Cancer Institute

\section{Source}

National Cancer Institute. PSA Level Less than One Hundred. NCI Thesaurus. Code C153422.

A blood concentration of prostate specific antigen less than $100 \mathrm{ng} / \mathrm{mL}$. 